\title{
PERIPHERAL VASCULAR TRAUMA- A LIMB MAY BE SAVED
}

\author{
Hemlata Verma1 , Ram Swaroop Sain², Deepak Sethi ${ }^{3}$ Anjali Sethi ${ }^{4}$
}

${ }_{1}^{1}$ Assistant Professor, Department of Cardiothoracic and Vascular Surgery, Sawai Man Singh Medical College, Jaipur, Rajasthan. ${ }^{2}$ Assistant Professor, Department of Cardiothoracic and Vascular Surgery, Sawai Man Singh Medical College, Jaipur, Rajasthan. ${ }^{3}$ Consultant Surgeon and Senior Specialist, Department of Surgery, Rabindranath Tagore Medical College, Udaipur, Rajasthan. ${ }_{4}^{4}$ Associate Professor, Department of Surgery, Ananta Institute of Medical Sciences, Kaliwas, Rajsamand, Rajasthan.

\section{ABSTRACT}

\section{BACKGROUND}

The incidence of vascular trauma has increased considerably during the past 40 years. Although, they represent less than $3 \%$ of all injuries, they deserve special attention because of complications and limb loss.

\section{MATERIALS AND METHODS}

This was a descriptive study. Over a period of one year, 98 patients were operated for peripheral vascular injuries. Physical examination was used for diagnosis with the use of duplex ultrasonography/ CT angiography where needed. Vascular repair was carried out in terms of primary repair or interposition vein graft and fasciotomy was considered as and when required. Patients with non-salvageable extremity requiring primary amputation were excluded from the study.

\section{RESULTS}

Most of the patients were male. Most common cause was road traffic accidents. Occurrence of concomitant orthopaedic injuries was very high in this study. The commonly injured artery was popliteal artery (38.7\%) and brachial artery (27.5\%). Surgical procedures performed were interposition vein grafts in $54 \%$ cases, whereas end-to-end repair in $20.4 \%$ cases. The limb salvage rate was $76.53 \%$.

\section{CONCLUSION}

Early diagnosis and treatment of vascular injury is important for limb salvage. Patients should be surgically intervened even after golden period has passed, because with limb or without limb matters a lot.

\section{KEYWORDS}

Vascular Trauma, Interposition Vein Graft, Limb Salvage, Vascular Repair, Road Traffic Accidents.

HOW TO CITE THIS ARTICLE: Verma H, Sain RS, Sethi D, et al. Peripheral vascular trauma- a limb may be saved. J. Evolution Med. Dent. Sci. 2018;7(14):1732-1736, DOI: 10.14260/jemds/2018/391

\section{BACKGROUND}

Vascular trauma is a fast growing emergency for vascular surgeons. The incidence of vascular trauma has increased considerably during the past 40 years. Vascular injuries comprise of $3 \%$ of all civilian traumas and continue to have significant associated morbidity and mortality in the 21st century.[1] Although, they represent only $3 \%$ of all injuries, they deserve special attention because of complications and limb loss.

Various common mechanism of injury seems to differ in different parts of the world[2,3] and include blunt and penetrating trauma, stab wound, gunshot wound and RTA with later being the most common cause in majority of cases.[4] In view of urgent need of intervention, usually physical examination is used for diagnosis with the use of duplex ultrasonography/ CT angiography where critically indicated. CTA provides accurate and timely diagnosis of peripheral vascular injuries and challenges the gold standard of arteriogram. ${ }^{[5]}$

'Financial or Other Competing Interest': None.

Submission 22-02-2018, Peer Review 20-03-2018,

Acceptance 26-03-2018, Published 02-04-2018.

Corresponding Author:

Dr. Ram Swaroop Sain,

\#109, J-Block, Sector-14, Hiran Magri,

Udaipur-313002, Rajasthan, India.

E-mail:dr.rssain68@gmail.com Deepanjali.d1972@gmail.com

DOI: $10.14260 /$ jemds/2018/391

\section{(c) (i) $(9)$}

In the past attempts to control arterial bleeding were by means of cauterisation method, manual compression and pouring boiling liquid materials on the wounds. Ambroise Pare initially used the ligation method during XVI century.[4] While first and second world wars gave knowledge of diagnosis and treatment of vascular injuries, vascular reconstructive methods were mainly introduced during the Korean and Vietnamese wars with a tremendous progress ${ }^{[3,4]}$ and a dramatic decrease in amputation rate.[2,3,6,7] Successful treatment of major arterial injuries is life-saving and allows limb salvage with restoration of function[6]; however, return of function also depends on concomitant nerve injury. [7]

Vascular trauma is associated with major morbidity and mortality, but little is known about its incidence or nature in our region. This study was done in 98 patients who underwent operative intervention for vascular trauma. This report presents the different mechanisms of vascular trauma, arteries involved, associated bone or nerve injuries and types of vascular intervention done and specially limb salvage rate at our centre. Injury to major peripheral artery causes limb ischaemia and if not repaired at proper time then can lead to loss of limb. That is why vascular trauma should be dealt within $6 \mathrm{hrs}$. of injury, which is called as golden period. But at our centre most of the patients present after passing of these golden hours because of delay in diagnosis or transportation. Still we moved on to repair these limb-threatening arterial injuries and got good limb saving results. We excluded crushed injuries, badly infected wound, limb with gangrenous changes and injuries presented after $100 \mathrm{hrs}$. 


\section{Objectives}

The objective of this study was to find out salvageability of limb in case of vascular injury to limb; particularly when patients present late. This study was done to analyse the outcome of peripheral vascular injuries in the form of limb salvage after surgical intervention.

\section{MATERIALS AND METHODS}

This was a descriptive study. In this study, 98 patients were included who presented with peripheral vascular injuries over a period of one year in CTVS Department of SMS Medical College, Jaipur, Rajasthan, India. All patients underwent physical examination and immediate management according to the principles of the Advanced Trauma and Life Support (ATLS) guidelines of trauma management. The patients were assessed in casualty and were referred to CTVS Department after finding absent pulsations in one or more limbs. In view of urgent need of intervention, physical examination was used for diagnosis with the use of duplex ultrasonography/CT angiography where critically indicated. Pre-operative duplex ultrasonography/CT angiography was done in patients with multiple fracture sites.

Patients with non-salvageable extremity requiring primary amputation or those who presented after 100 hours of injury were excluded from the study.

Patients were taken immediately to the operating room for vascular, orthopaedic and plastic surgery management. In patients with associated bony injuries, orthopaedic intervention was done first. Thorough debridement of wound with removal of foreign bodies and copious irrigation with isotonic saline was done in all patients. Management of vascular injuries was done in the operating room under general anaesthesia or spinal/epidural anaesthesia using standard vascular techniques. Vascular repair was carried out in terms of primary repair or interposition vein graft. Repaired vessels were covered with muscles and soft tissues to prevent desiccation and disruption. If needed suitable covers for the defect were given by Plastic Surgeons with split skin grafting (SSG) techniques. Fasciotomy was considered as and when required.

Successful repair was assessed by the return of distal pulses at the end of operation. Associated nerve injuries were repaired at the time of vascular repair and injury to major veins were also repaired to minimise postoperative oedema and compartment syndrome. Antibiotics were given for five to seven days unless prolonged use was dictated by presence of contamination or infection. All patients also received intravenous heparin for a period of 3 days postoperatively and oral anticoagulants were started after patient started to take orally. Patients were discharged on oral anticoagulants and anti-platelets.

\section{Statistical Analysis}

Data was analysed using SPSS Version 16.0. The qualitative data were expressed as numbers and percentages.

\section{RESULTS}

A total of 98 patients were operated for vascular injury over a period of one year. Road traffic accident (RTA) was the commonest cause of peripheral vascular injury (60.20\%). Other forms of trauma were penetrating injury (16.32\%), fall from height (9.18\%), industrial or machinery like electric saw or hand drilling machines (2.04\%), gunshot (2.04\%) and stab injuries. One interesting mode of vascular injury was camel bite, which accounted for $6 \%$ cases. Males were the main victims accounting for $93 \%$ cases and females were $7 \%$ with male-to-female ratio of 19: 1 .

Vascular trauma was more common in lower limb $(60.20 \%)$ in comparison to upper limb (39.79\%). Most commonly injured arteries were popliteal (37.75\%), brachial (26.53\%) and femoral (18) with radial, ulnar, posterior tibial and axillary artery in 7, 4, 4, 2 cases respectively (Table 1).

Successful outcome in vascular trauma depends on early diagnosis and intervention. In our set-up, majority of the patients presented beyond the duration that is considered as the "Golden Period."

Patients usually presented after 6 hrs. Only 19\% patients presented within $6 \mathrm{hrs}$. With $46 \%$ patients in 7 to $12 \mathrm{hrs}$., 5 patients after $72 \mathrm{hrs}$., 2 after $81 \mathrm{hrs}$. and 3 patients presented after 4 days (Table 2). The time interval between beginning of the trauma and arrival to our centre was a mean of 24 hours. The causes of delayed presentation were delayed recognition of vascular injury and delay in transport. Presence of open arterial bleeding, presence of an increased intended or pulsated haematoma, presence of six 'P' signs (Pulselessness, Poikilothermia, Pallor, Pain, Paraesthesia, Paralysis) of the related extremities formed the basis of diagnosis with Computed Tomographic angiography done only in 9 cases (9.1\%) with multiple fracture sites.

Orthopaedic injuries were seen in $65 \%$ cases with nerve and vein injuries seen in 12 and 19 cases respectively. Contusion was the most common pattern of arterial injury (49\%) cases followed by complete transection (29\%). Spasm, partial transection and multiple site injury were seen in $10 \%$, $7 \%$ and $3 \%$ cases respectively. Only one case of traumatic AV fistula was seen (Table 3). No intervention was done in 2 cases, because after exposing the artery pulsations were present with no visible vascular injury. Reversed saphenous vein interposition graft was used most commonly to repair the artery (53\%) with end-to-end repair was done in $20 \%$ cases and PTFE graft was used in 3\% cases. Ligation was done in 6 cases (Table 4). A balloon embolectomy catheter was used to remove thrombus and confirm patency proximally and distally.

Repair of major venous injuries was performed in 18 patients with primary repair in 3 , end-to-end repair in 8 , interposition vein graft in 6 and patch repair in 1 case and ligation of vein in one. Nerve repair was done in 7 cases.

In spite of presentation after 6 hours, the results of repair were extremely good. 18 out of 19 patients who presented within 6 hrs. achieved warm limb with palpable distal pulse. One case was sent for amputation, because of multiple injury of artery due to bomb blast. In 64 cases of delayed presentation, we were able to give warm limb with palpable pulses in 45 cases. In 14 cases of vascular repair limb remained cold, mainly in patients who presented after $24 \mathrm{hrs}$. (Table 5).

Postoperative complications in the form of infection was seen in 10 cases, secondary haemorrhage resulted in 3 patients (3\%) and 2 patients (2.04\%) died due to septicaemia (Table 6). 23 cases underwent amputation. 14 cases did not improve with surgery and had cold limb postoperatively (Table 7). 9 cases with warm limb were amputated due to secondary haemorrhage (3), blast injury (1), myonecrosis (3) 
due to delayed presentation and infection (1), while 1 case underwent toes amputation. Overall limb salvage rate was $76.53 \%$.

\begin{tabular}{|c|c|c|}
\hline Artery & No. of Cases & Percentage \\
\hline Axillary & 2 & 2.08 \\
\hline Brachial & 26 & 26.53 \\
\hline Radial & 7 & 7.14 \\
\hline Ulnar & 4 & 4.08 \\
\hline Femoral & 18 & 18.36 \\
\hline Popliteal & 37 & 37.75 \\
\hline Posterior tibial & 4 & 4.08 \\
\hline Total Table 1. Artery Involved \\
\hline \multicolumn{3}{|c|}{} \\
\hline
\end{tabular}

\begin{tabular}{|c|c|c|}
\hline Time (Hours.) & No. of Cases & Percentage \\
\hline $0-6$ & 19 & 19.38 \\
\hline $7-12$ & 40 & 40.82 \\
\hline $13-19$ & 5 & 5.10 \\
\hline $20-25$ & 10 & 10.20 \\
\hline $26-30$ & 4 & 4.09 \\
\hline $31-40$ & 1 & 1.02 \\
\hline $41-50$ & 7 & 7.15 \\
\hline $51-60$ & 2 & 2.04 \\
\hline $61-70$ & 0 & 0 \\
\hline $71-80$ & 5 & 5.10 \\
\hline $81-90$ & 2 & 2.04 \\
\hline $91-100$ & 3 & 3.06 \\
\hline Total & 98 & $\mathbf{1 0 0}$ \\
\hline \multicolumn{2}{|c|}{ Table 2. Time of Presentation } \\
\hline
\end{tabular}

\begin{tabular}{|c|c|c|}
\hline Injury & No. of Cases & Percentage \\
\hline Contusion & 48 & 48.97 \\
\hline Spasm & 10 & 10.20 \\
\hline Partial transection & 7 & 7.14 \\
\hline $\begin{array}{c}\text { Complete } \\
\text { transection }\end{array}$ & 29 & 29.59 \\
\hline Multiple sites & 3 & 3.06 \\
\hline AV fistula & 1 & 1.02 \\
\hline Total Table 3. Arterial Injury \\
\hline \multicolumn{2}{|c|}{} \\
\hline
\end{tabular}

\begin{tabular}{|c|c|c|}
\hline Repair & No. of Cases & Percentage \\
\hline No intervention & 2 & 2.04 \\
\hline Embolectomy & 10 & 10.20 \\
\hline Lateral sutures & 4 & 4.08 \\
\hline End-to-end repair & 20 & 20.40 \\
\hline Vein graft & 53 & 54.08 \\
\hline PTFE graft & 3 & 3.06 \\
\hline Ligation & 6 & 6.12 \\
\hline Total & $\mathbf{9 8}$ & $\mathbf{1 0 0}$ \\
\hline \multicolumn{2}{|c}{ Table 4. Arterial Repair } \\
\hline
\end{tabular}

\begin{tabular}{|c|c|c|}
\hline Result & No. of Cases & Percentage \\
\hline Warm limb & 84 & 85.71 \\
\hline Pulse present & 63 & 64.28 \\
\hline Pulse absent & 21 & 21.42 \\
\hline Cold limb & 14 & 14.28 \\
\hline Total & $\mathbf{9 8}$ & $\mathbf{1 0 0}$ \\
\hline \multicolumn{2}{|c|}{ Table 5. Result of Vascular Repair } \\
\hline
\end{tabular}

\begin{tabular}{|c|c|c|}
\hline Complication & No. of Cases & Percentage \\
\hline Bleeding & 3 & 3.06 \\
\hline Infection & 10 & 10.20 \\
\hline
\end{tabular}

\begin{tabular}{|c|c|c|}
\hline Amputation & 23 & 23.46 \\
\hline Death & 2 & 2.04 \\
\hline \multicolumn{3}{|c|}{ Table 6. Complication } \\
\hline
\end{tabular}

\begin{tabular}{|c|c|c|}
\hline Limb Condition & No. of Cases & Percentage \\
\hline Cold limb & 14 & 14.28 \\
\hline Warm limb & 9 & 9.18 \\
\hline Total Amputation & $\mathbf{2 3}$ & $\mathbf{2 3 . 4 6}$ \\
\hline \multicolumn{2}{|c|}{ Table 7. Amputation } \\
\hline
\end{tabular}

\section{DISCUSSION}

Despite modern surgical interventions, vascular injuries can still cause extremity loss and even death. According to some authors, amputation rates can even reach $78 \% .{ }^{[8]}$ In our study amputation rate was $23 \%$, while it was $6 \%,[9,10] 7.7 \%,[11]$ $14.6 \%[7]$ and $17.24 \%{ }^{[12]}$ in other studies. The extremity salvage in our study was $76.53 \%$, while it was $84 \%,[7,9,11]$ $94 \%{ }^{[10]}$ and $95 \%{ }^{[13]}$ in others. Cause of less percentage of limb salvage may be due to delayed presentation.

Successful outcome in vascular trauma depends on early diagnosis and intervention. In our set-up, majority of the patients presented beyond what is considered as the "Golden Period."

In this study Road traffic injury was the commonest cause (60\%), mainly in male patients. This may be due to population and road discrepancy. Also women usually do not prefer driving in our region. Vascular injuries are frequent among young male population, $[7,9,10,14]$ and in this study male patients composed of $93 \%$ of the cases with lower limb involvement (60.20\%), more common than upper limb (39.79\%).

Vessels, nerves and bones may be injured together due to their close relation anatomically.[15,16]

In our study, popliteal artery was the most commonly injured artery $(37.75 \%)$ followed by brachial artery (26.53\%).

Bone fractures and nerve lesions in this study involved $65 \%$ and $12 \%$ of cases respectively. The patients with bone fracture, nerve injury and severe soft tissue injuries were assessed by related disciplines and appropriate intervention was done. In our patients with fractures external fixation was more preferred because of easier application and low infection risk.

Peripheral angiography in vascular injuries is controversial. Some authors are suggesting angiography to every pre-operative patient. $[8,17,18,19]$ Many clinicians report their successful vascular injury results without angiography.[7,14,20,21] We followed only clinical diagnostic method for early intervention and peripheral angiography was only done in cases with multilevel vascular and orthopaedic injuries. In all the patients with associated orthopaedic injuries, the orthopaedic surgeon performed reduction and fixation of fracture and/ or dislocation prior to the vascular repair. In one study, end-to-end repair was done in $26.75 \%$, vein graft in $21 \%$, PTFE graft in $1.9 \%$ and ligation in $8.9 \%$ cases. [7]

Reversed saphenous vein interposition graft in this study was used most commonly to repair the artery (53\%) with end-to-end repair done in 20\% cases and PTFE graft was used in $3 \%$ cases, while in another study primary repair in $55.5 \%$ cases and vein graft $35.2 \%$ cases. ${ }^{[10]}$ Ligation was done in 6 cases. 
In repairing damaged blood vessels, lifesaving measures take precedence over limb-saving procedures; at exploration, proximal and distal arterial control must be established before repair is attempted; vascular reconstruction is preferable to ligation; and the best evidence of good repair is restoration of the distal pulses. These principles are based on experience with 125 peripheral vascular injuries in Vietnam.[22]

Endovascular interventions (EVIs) are an important adjunct to open surgical management of peripheral vascular injuries. In appropriate situations EVIs decrease operative time, estimated blood loss and iatrogenic complications when compared with similar surgical cohorts by limiting surgical dissection in traumatised operative fields.[23]

A well-stabilised skeleton is essential before definitive arterial and soft tissue repair can be performed. [24] However, Hunt et al suggested that arterial revascularisation should be followed by skeleton stabilisation and nerve and tendon repair.[25] In this study, skeleton fixation was done prior to vascular repair. In arterial injuries successful results were obtained in arterial reconstruction procedures, which were held 6 - 8 hours after the event.[18,26] Almost, all of the amputation performed in our study were late cases that were revascularised after 8 hours of injury. Infection is also a major factor, which increases amputation rate after a successful vascular surgery. For this reason, vigorous and appropriate tissue debridement is important before and after the revascularisation procedure.[27] In our study 10 patients developed infection, but amputation was done in only one case.

\section{Abbreviations \\ CTA: Computed Tomographic Angiography. RTA: Road Traffic Accident. \\ ATLS: Advanced Trauma and Life Support. \\ CTVS: Cardiothoracic and Vascular Surgery. \\ SSG: Split Skin Grafting. \\ EVI: Endovascular Intervention.}

\section{CONCLUSION}

Early diagnosis and treatment of vascular injury is important for limb salvage. Patients should be surgically intervened even after golden period has passed, because with limb or without limb matters a lot.

\section{REFERENCES}

[1] Compton C, Rhee R. Perspectives in vascular surgery and endovascular therapy-peripheral vascular trauma. Sage Journals 2005;17(4):297-307.

[2] Creagh TA, Broe PJ, Grace PA, et al. Blunt traumainduced upper extremity vascular injuries. J R Coll Surg Edinb 1991;36(3):158-60.

[3] Weaver FA, Hood DB, Yellin AE. Vascular injuries of the extremities. In: Rutherford RB, edr. Vascular Surgery. $5^{\text {th }}$ edn. WB Saunders Company 2000: p. 6271.

[4] Mattox KL, Hirshberg A. Vascular trauma. In: Haimovici H, Ascer E, Hollier LH, et al. eds. Haimovici's vascular surgery. $4^{\text {th }}$ edn. USA: Blackwell Science 1996: p. 480-96.
[5] Peng PD, Spain DA, Tataria M, et al. CT angiography effectively evaluates extremity vascular trauma. The American Surgeon 2008;74(2):103-7.

[6] Feliciano DV, Bitondo CG, Mattox KL, et al. Civilian trauma in the 1980s. A 1 year experience with 456 vascular and cardiac injuries. Ann Surg 1984;199(6):717-24.

[7] Razmadze A. Vascular injuries of the limbs: a fifteenyear Georgian experience. Eur J Vasc Endovasc Surg 1999;18(3):235-9.

[8] Andrikopoulos V, Antoniou I, Panoussis P. Arterial injuries associated with lower-extremity fractures. Cardiovasc Surg 1995;3(1):15-8.

[9] Menakuru SR, Behera A, Jindal R, et al. Extremity vascular trauma in civilian population: a seven-year review from North India. Injury 2005;36(3):400-6.

[10] Singh D, Pinjala RK. Management of peripheral vascular trauma: our experience. The Internet Journal of Surgery 2004;7:1-7.

[11] Aduful HK, Hodasi WM. Peripheral vascular injuries and their management in Accra. Ghana Med J 2007;41(4):186-9.

[12] Sun YF, Fang QF, Zhan HY, et al. Outcome assessments of patients with post traumatic "ultra-time vascular injuries" of the extremities. Sci Rep 2015;5:17913.

[13] Starnes BW, Bruce JM. Popliteal artery trauma in a forward deployed mobile Army Surgical hospital: lessons learned from the war in Kosovo. J Trauma 2000;48(6):1144-7.

[14] Mattox KL. Thoracic vascular trauma. J Vasc Surg 1988;7(5):725-9.

[15] Klein SR, Bongard FS, White RA. Neurovascular injuries of the thoracic outlet and axilla. Am J Surg 1988;156(2):115-8.

[16] Weaver FA, Rosenthal RE, Waterhouse G, et al. Combined skeletal and vascular injuries of the lower extremities. Am Surg 1984;50(4):189-97.

[17] Johansen K, Lynch K, Paun M, et al. Non-invasive vascular tests reliably exclude occult arterial trauma in injured extremities. J Trauma 1991;31(4):515-9, discussion 515-22.

[18] Yilmaz AT, Arslan M, Demirkiliç U, et al. Missed arterial injuries in military patients. Am J Surg 1997;173(2):110-4.

[19] Solak H, Yeniterzi M, Yüksek T, et al. Injuries of the peripheral arteries and their surgical treatment. Thorac Cardiovasc Surg 1990;38(2):96-8.

[20] Anderson RJ, Hobson RW, Lee BC, et al. Reduced dependency on arteriography for penetrating extremity trauma: influence of wound location and non-invasive vascular studies. J Trauma 1990;30(9):1059-63, discussion 1063-5.

[21] Peck JJ, Eastman AB, Bergan JJ, et al. Popliteal vascular trauma. A community experience. Arch Surg 1990;125(10):1339-44.

[22] Bizer LS. Peripheral vascular trauma. Postgraduate Medicine 2016;49, 1971(2):127-30.

[23] Johnson CA. Endovascular management of peripheral vascular trauma. Semin Intervent Radiol 2010;27(1):38-43. 


\section{Jemds.com}

[24] Flecther JP, Little JM. Vascular trauma. Aust N Z J Surg 1981;51(4):333-6.

[25] Hunt CA, Kingsley JR. Vascular injuries of the upper extremity. South Med J 2000;93(5):466-8.

\section{Original Research Article}

[26] Padberg FT, Rubelowsky JJ, Hernandez-Maldonado JJ, et al. Infrapopliteal arterial injury: prompt revascularization affords optimal limb salvage. J Vasc Surg 1992;16(6):877-86.

[27] Flint LM, Richardson JD. Arterial injuries with lower extremity fracture. Surgery 1983;93(1 Pt 1):5-8. 